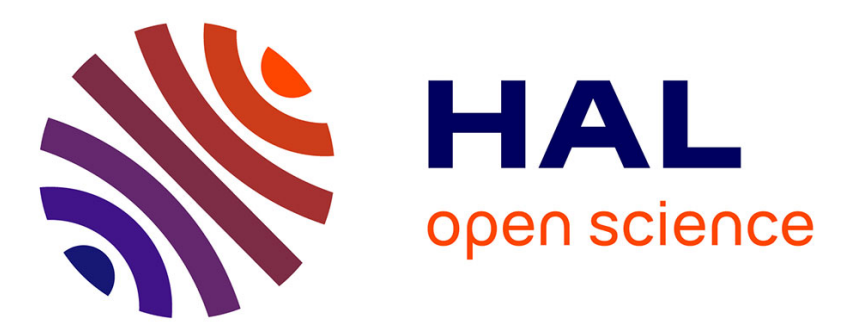

\title{
In vitro and in vivo bimodal effects of docosahexaenoic acid supplements on redox status and platelet function
}

\author{
Michel Lagarde, Catherine Calzada, Michel Guichardant, Evelyne Véricel
}

\section{To cite this version:}

Michel Lagarde, Catherine Calzada, Michel Guichardant, Evelyne Véricel. In vitro and in vivo bimodal effects of docosahexaenoic acid supplements on redox status and platelet function. Prostaglandins, Leukotrienes and Essential Fatty Acids, 2016, 138, Epub ahead of print. 10.1016/j.plefa.2016.05.010 . inserm-01299786

\section{HAL Id: inserm-01299786 https://www.hal.inserm.fr/inserm-01299786}

Submitted on 8 Apr 2016

HAL is a multi-disciplinary open access archive for the deposit and dissemination of scientific research documents, whether they are published or not. The documents may come from teaching and research institutions in France or abroad, or from public or private research centers.
L'archive ouverte pluridisciplinaire HAL, est destinée au dépôt et à la diffusion de documents scientifiques de niveau recherche, publiés ou non, émanant des établissements d'enseignement et de recherche français ou étrangers, des laboratoires publics ou privés. 


\title{
In vitro and in vivo bimodal effects of docosahexaenoic acid supplements on redox status and platelet function
}

Michel Lagarde, Catherine Calzada, Michel Guichardant, and Evelyne Véricel

Lyon University, Inserm UMR 1060, Inra UMR 1397 (CarMeN Laboratory), IMBL, INSA-Lyon, Villeurbanne, France.

\begin{abstract}
Docosahexaenoic acid (DHA) is a prominent nutrient of marine lipids. Together with eicosapentaenoic acid, it is recognized as a protective molecule against atherosclerosis and thrombosis through the regulation of blood cell functions, especially platelets. Its high unsaturation index may however make it prone to peroxidation, which is usually considered as deleterious. This short review takes into consideration this possibility related to DHA concentrations both in vitro and in vivo. It is suggested that protective effects of DHA on platelet activation depend on the reduction of oxidative stress, and appear bimodal with the abolishment of such a protection when DHA is used at relatively high concentrations.
\end{abstract}

\section{Introduction}

Docosahexaenoic acid (DHA) is one of the long-chain polyunsaturated fatty acids (PUFA) of the omega-3 family found in marine lipids. Together with eicosapentaenoic acid (EPA), DHA is wellknown for its anti-atherothrombotic potential, in particular by decreasing the arachidonic acid ( $\operatorname{ArA})$ content of blood cells [1], inhibiting thromboxane production in platelets, as well as leukotriene $B_{4}$ formation in leukocytes [2].

In addition to these inhibitory effects on ArA metabolism, DHA may decrease athero-thrombogenesis through the action of its lipoxygenase (LOX) end-products. Mono-hydroxylated derivatives produced through 12-, and 15-LOX, namely 11-, 14-, and 17-OH-22:6 (11-, 14-, and 17-HDoHE), respectively, inhibit the thromboxane-induced platelet aggregation (induced by the stable thromboxane $A_{2}$ receptor agonist U-46619), even stronger than 12-OH-20:4 and -20:5 (12-HETE and -HEPE) [3]. More recently, the double lipoxygenase product of DHA, 10(S),17(S)-diHDoHE, named protectin DX, has been shown to inhibit platelet aggregation through the inhibition of cyclooxygenase-1, which initiates prostanoid synthesis including the potent pro-aggregatory thromboxane $A_{2}$, as well as the response to the thromboxane $A_{2}$ mimetic $U-46619$ [4]. In addition, DHA is known to be oxygenated into several di/tri-OH derivatives (protectin D1, maresins, and resolvins) that are potent inhibitors of the inflammation process [5].

Supplementation of humans with long-chain omega-3 PUFA is usually considered as a positive approach to decrease the risk of atherosclerosis and thrombosis [6], as recently reviewed [7], although some controversies arose in the recent years [8]. Among the controversial issues are the intake doses of those highly unsaturated PUFA, which may be prone to peroxidation [9]. We have been especially interested in the effects of different concentrations of DHA upon blood platelets and their blood environment both in vitro and in vivo, in particular regarding the redox status.

\section{In vitro effects of DHA on platelet reactivity and redox status}

When compared with EPA, DHA pre-incorporated in human platelet phospholipids was more potent to inhibit platelet aggregation induced by various agonists. While EPA was substantially released, and oxygenated like endogenous ArA in response to thrombin, DHA was preferentially transferred from phosphatidylcholine to phosphatidylethanolamine [10], especially their plasmalogen subclass [11]. One possible mechanism for the high potential of DHA to inhibit thrombin-induced platelet aggregation is the strongest inhibition of endogenous ArA oxygenation by cyclooxygenase, while the lipoxygenase activity was not altered [12]. The cyclooxygenase inhibition by DHA was however alleviated by doubling the concentration of DHA added to platelets, without altering the inhibition of 
platelet aggregation, presumably because prostaglandin $D_{2}$ formation, a potent inhibitor of platelet aggregation, was increased [13]. We might speculate that such a paradoxical effect might be explained by the oxidative stress induced by high concentrations of DHA, which could have increased the cyclooxygenase activity (see later results below). In addition to the inhibition of platelet cyclooxygenase by DHA enrichment, the response of DHA-rich platelets to the thromboxane $A_{2}$ mimetic U-46619 was strongly inhibited through the decreased affinity of this agonist to its membrane receptor sites [14]. Another platelet function, the pro-coagulant activity of platelet phosphatidylserine exposure in response to collagen, can be altered by DHA (or EPA) enrichment in vitro. Again, the inhibitory effect of those PUFA, only significant at $0.75 \mathrm{mM}$, was not increased by doubling their concentration [15].

Considering the high unsaturation of long-chain omega-3 PUFA, especially DHA, it is likely that lipid peroxidation will be favored when their concentrations are increased in biological systems. Indeed, PUFA, and in particular DHA, increase free radical formation in oxidative stress conditions [9]. We have been interested in the dose-related effect of DHA on human platelet redox status after in vitro enrichment. A dose-dependent increased DHA concentration in membrane phospholipids (phosphatidylcholine and phosphatidylethanolamine) after incubation with albumin-bound DHA (DHA/albumin ratios of $0.01,0.1$, and 1 , corresponding to $0.5,5$, and $50 \mu \mathrm{M}$ ) was observed but, at the lowest concentration, this was only significant in the plasmalogen ethanolamine subclass. This observation has been discussed regarding the potential antioxidant activity of the plasmalogen subclass [16]. Malondialdehyde (MDA) and the 12-lipoxygenase end-product 12-HETE, measured as markers of oxidative stress, were significantly increased after the highest enrichment, but significantly decreased at the lowest one. These results suggest a bimodal effect according to DHA concentrations, with an interesting protection against lipid peroxidation at low concentrations [16]. The increased peroxidation observed after the highest enrichment was in agreement with significant decreased platelet alpha- and gamma-tocopherols.

\section{In vivo effects of DHA on platelet function and their blood environment}

As a component of long-chain omega-3 PUFA, DHA intake has long been reported a protective agent against atherosclerosis and thrombosis as recently reviewed $[6,7,17,18]$, acting through several ways. One of them is the inhibition of blood platelet activation via mechanisms already mentioned above such as competition with ArA metabolism, especially thromboxane formation. However, metaanalyses revealed heterogeneities in results that might be due to different intake doses [8], and high daily supplementation may decrease antioxidant defenses such as alpha-tocopherol in plasma [19]. Considering the deleterious effect of oxidative stress in platelet [20-23] and blood mononuclear cell functions [24], we have investigated the relationship between the doses of DHA intake and the reactivity of those cells.

In a study with healthy human volunteers, increasing doses $(200,400,800$, and $1600 \mathrm{mg} /$ day) of DHA in triacylglycerols from micro-algae were consumed for two-weeks each dose. There was a dosedependent increase of DHA in plasma phospholipids, as well as in platelet phosphatidylcholine and phosphatidylethanolamine. Whether, the increase in phosphatidylethanolamine reflected a preferential incorporation within their plasmalogen subclass, as found in vitro (see above), was not investigated. In terms of platelet reactivity, the dose-response was bimodal with a maximal inhibition of platelet aggregation and cyclo-oxygenation of exogenous ArA after $800 \mathrm{mg} /$ day DHA. After 1600 $\mathrm{mg} /$ day DHA, the aggregation was less inhibited and cyclo-oxgenase activity was not significantly altered [25]. In addition, platelet vitamin E (alpha-tocopherol) significantly increased after 200 $\mathrm{mg} /$ day DHA. In agreement with this increased antioxidant status in platelets, urinary isoprostanes (8-epi-PGF $F_{2 \alpha}$ ), as a marker of the global redox status, were significantly decreased after this low dose intake of DHA, whereas they were significantly increased after $1600 \mathrm{mg} /$ day DHA [25]. This clearly suggests that low dosages of DHA are protective against platelet-related atherothrombotic risk in relation with an antioxidant effect at low dosage of DHA, whereas the highest dose tested (1600 $\mathrm{mg} /$ day DHA) was less potent against platelet reactivity, possibly because of an increased oxidative stress. 
Plasma low-density lipoproteins (LDL) were also studied in response to the different doses of DHA. LDL cholesterol esters and phospholipids were dose-dependently enriched in DHA according to the intake doses. However, a bimodal effect of this DHA enrichment could be observed, with a significant increase of LDL alpha-tocopherol content, and decrease of LDL MDA after 200, 400, and $800 \mathrm{mg}$ DHA/day, but not after $1600 \mathrm{mg}$. Interestingly, the lag phase in the copper-induced oxidation of LDL was similarly increased after those three doses but not after the highest dose, meaning that the intermediary doses of DHA may protect against LDL oxidation. Although not significantly different from the other doses, the most active dose in such a protection, and MDA decrease was observed after $400 \mathrm{mg} /$ day DHA [26].

In parallel, the apoptosis of blood mononuclear cells induced by oxidized LDL was tested. While there was a dose-dependent correlation in the IL-2 transcript expression with DHA intake, monocyte apoptosis was significantly attenuated after $400 \mathrm{mg} / \mathrm{day} \mathrm{DHA}$, and such a protective effect was maintained at higher doses, although to a lesser extent [27].

Altogether, these results obtained in healthy volunteers strongly suggest that daily doses of DHA lower than one gram should be recommended to decrease the athero-thrombotic risk related to blood cell reactivity, especially platelets. Several markers even suggest that the most active daily doses of DHA might be lower than $500 \mathrm{mg}$. In agreement with these dose-effect investigations in healthy volunteers, it has previously been shown that low daily doses of DHA + EPA $(150+30 \mathrm{mg})$ exhibit the same protective effects in elderly people, through a reduction of oxidative stress [28]. The effects of different intake doses of DHA in healthy human volunteers has been recently reviewed [29]. Interestingly, and more recently, the intake of $400 \mathrm{mg} /$ day DHA in type-2 diabetic patients has shown similar protection, with even more potency than in healthy volunteers. Indeed, platelet aggregation was decreased by $50 \%$, several markers of oxidative stress were significantly decreased, and vitamin E was significantly increased in both blood plasma and platelets [30]. This suggests that the higher the oxidative stress, the higher the efficiency of DHA moderate intake to decrease such a stress.

The mechanism underlying such a protection through a decreased oxidative stress is not clear. We might however speculate that DHA being easily oxidized, it might have a trapping effect of oxidant species at low doses, then saving vitamin $\mathrm{E}$ as observed in several studies, although participating in the oxidative stress at high concentrations. In favor of this hypothesis is the observation that a dosedependent formation of 4-hydroxy-hexenal, one specific peroxidation by-product from omega-3 PUFA, was observed after DHA intake, while 4-hydroxy-nonenal, the counter peroxidation by-product from omega-6 PUFA, did not change [26].

\section{Conclusion}

The long-chain omega-3 PUFA DHA and EPA, in particular DHA, are useful nutrients to protect against the athero-thrombotic risk associated with blood platelet reactivity. DHA effect at moderate concentrations, both in vitro and in vivo, might be related to reduction of oxidative stress (Figure 1). This would be especially useful in situations where the redox status is altered toward oxidation such as aging and diabetes.

\section{Acknowledgements}

The authors thank the current support of Inserm, Inra, and the Ministry of Education and Research, as well as that of a grant from the "Coeur \& Artères" foundation.

\section{References}

[1] A.A. Spector, Essentiality of fatty acids. Lipids 34 (1999) Suppl:S1-3. Review. 
[2] J.E. Kinsella, B. Lokesh, R.A. Stone, Dietary n-3 polyunsaturated fatty acids and amelioration of cardiovascular disease: possible mechanisms, Am J Clin Nutr 52 (1990) 21-28. Review.

[3] M. Croset, A. Sala, G. Folco, M. Lagarde, Inhibition by lipoxygenase products of TXA2-like responses of platelets and vascular smooth muscle. 14-Hydroxy from 22:6n-3 is more potent than 12HETE, Biochem Pharmacol 37 (1988) 1275-1280.

[4] P. Chen, E. Véricel, M. Lagarde, M. Guichardant, Poxytrins, a class of oxygenated products from polyunsaturated fatty acids, potently inhibit blood platelet aggregation, FASEB J 25 (2011) 382-388.

[5] C.N. Serhan, Pro-resolving lipid mediators are leads for resolution physiology, Nature 510 (2014) 92-101.

[6] P.J. Nestel, Fish oil and cardiovascular disease: lipids and arterial function, Am J Clin Nutr 71 (2000) 228S-2231S. Review.

[7] D. Kromhout, J. de Goede, Update on cardiometabolic health effects of $\omega-3$ fatty acids, Curr Opin Lipidol 25 (2014) 85-90. Review.

[8] E.C. Rizos, E.E. Ntzani, E. Bika, M.S. Kostapanos, M.S. Elisaf, Association between omega-3 fatty acid supplementation and risk of major cardiovascular disease events: a systematic review and metaanalysis. JAMA 308 (2012) 1024-1033. Review.

[9] J.A. North, A.A. Spector, G.R. Buettner, Detection of lipid radicals by electron paramagnetic resonance spin trapping using intact cells enriched with polyunsaturated fatty acid, J Biol Chem 267 (1992) 5743-5746.

[10] M. Croset, M. Lagarde, In vitro incorporation and metabolism of icosapentaenoic and docosahexaenoic acids in human platelets--effect on aggregation, Thromb Haemost 56 (1986) 57-62.

[11] M. Croset, Y. Bayon, M. Lagarde, Incorporation and turnover of eicosapentaenoic and docosahexaenoic acids in human blood platelets in vitro, Biochem J 281 (1992) 309-316.

[12] M. Croset, M. Guichardant, M. Lagarde, Different metabolic behavior of long-chain $n-3$ polyunsaturated fatty acids in human platelets, Biochim Biophys Acta 961 (1988) 262-269.

[13] D.C. Gaudette, B.J. Holub, Albumin-bound docosahexaenoic acid and collagen-induced human platelet reactivity, Lipids 25 (1990) 166-169.

[14] P.G. Swann, C.A. Parent, M. Croset, P. Fonlupt, M. Lagarde, V.L. Venton, G.C. Le Breton, Enrichment of platelet phospholipids with eicosapentaenoic acid and docosahexaenoic acid inhibits thromboxane A2/prostaglandin H2 receptor binding and function, J Biol Chem 265 (1990) 2169221697.

[15] M.K. Larson, G.W. Tormoen, L.J. Weaver, K.J. Luepke, I.A. Patel, C.E. Hjelmen, N.M. Ensz, L.S. McComas, O.J McCarty, Exogenous modification of platelet membranes with the omega-3 fatty acids EPA and DHA reduces platelet procoagulant activity and thrombus formation, Am J Physiol Cell Physiol 304 (2013) C273-279.

[16] E. Véricel, A. Polette, S. Bacot, C. Calzada, M. Lagarde, Pro- and antioxidant activities of docosahexaenoic acid on human blood platelets, J Thromb Haemost 1 (2003) 566-572. 
[17] GISSI (Gruppo Italiano per lo Studio della Sopravvivenza nell'Infarto miocardico)-PrevenzioneInvestigators, Dietary supplementation with $\mathrm{n}-3$ polyunsaturated fatty acids and vitamin $\mathrm{E}$ after myocardial infarction: results of the GISSI Prevenzione trial, Lancet 354 (1999) 447-455.

[18] P.M. Kris-Etherton, W.S. Harris, L.J. Appel, Fish consumption, fish oil, omega-3 fatty acids, and cardiovascular disease, Circulation 106 (2002) 2747-2757.

[19] T.A. Sanders, A. Hinds, The influence of a fish oil high in docosahexaenoic acid on plasma lipoprotein and vitamin $\mathrm{E}$ concentrations and haemostatic function in healthy male volunteers, $\mathrm{Br} \mathrm{J}$ Nutr 68 (1992) 163-173.

[20] M. Aviram, LDL-platelet interaction under oxidative stress induces macrophage foam cell formation, Thromb Haemost 74 (1995) 560-564. Review.

[21] S.K. Jain, K.S. Krueger, R. McVie, J.J. Jaramillo, M. Palmer, T. SmitH, Relationship of blood thromboxane-B2 (TxB2) with lipid peroxides and effect of vitamin $E$ and placebo supplementation on TxB2 and lipid peroxide levels in type 1 diabetic patients, Diabetes Care 21 (1998) 1511-1516.

[22] P. Ferroni, S. Basili, A. Falco, G. Davi, Oxidant stress and platelet activation in hypercholesterolemia, Antioxid Redox Signal 6 (2004) 747-756. Review.

[23] E. Véricel, C. Januel, M. Carreras, P. Moulin, M. Lagarde, Diabetic patients without vascular complications display enhanced basal platelet activation and decreased antioxidant status, Diabetes 53 (2004) 1046-1051.

[24] N. Meskini, G. Nemoz, P. Chapuy, P. Haond, J.F. Pageaux, E. Vericel, M. Lagarde, A.F. Prigent, Glutathione peroxidase activity and metabolism of arachidonic acid in peripheral blood mononuclear cells from elderly subjects, Clin Sci (Lond) 85 (1993) 203-211.

[25] N. Guillot, E. Caillet, M. Laville, C. Calzada, M. Lagarde, E. Véricel, Increasing intakes of the longchain omega-3 docosahexaenoic acid: effects on platelet functions and redox status in healthy men, FASEB J 23 (2009) 2909-2916.

[26] C. Calzada, R. Colas, N. Guillot, M. Guichardant, M. Laville, E. Véricel, M. Lagarde, Subgram daily supplementation with docosahexaenoic acid protects low-density lipoproteins from oxidation in healthy men, Atherosclerosis 208 (2010) 467-472.

[27] S. Mebarek, N. Ermak, A. Benzaria, S. Vicca, M. Dubois, G. Némoz, M. Laville, B. Lacour, E. Véricel, M. Lagarde, A.F. Prigent, Effects of increasing docosahexaenoic acid intake in human healthy volunteers on lymphocyte activation and monocyte apoptosis, Br J Nutr 101 (2009) 852-858.

[28] E. Véricel, C. Calzada, P. Chapuy, M. Lagarde, The influence of low intake of n-3 fatty acids on platelets in elderly people, Atherosclerosis 147 (1999) 187-192.

[29] M. Lagarde, C. Calzada, M. Guichardant, E. Vericel, Dose-effect and metabolism docosahexaenoic acid: Pathophysiological relevance in blood platelets, Protagl Leukot Essent Fatty 88 (2013) 49-52.

[30] E. Véricel, R. Colas, C. Calzada, Q.H. Lê, N. Feugier, C. Cugnet, H. Vidal, M. Laville, P. Moulin, M. Lagarde, Moderate oral supplementation with docosahexaenoic acid improves platelet function and oxidative stress in type 2 diabetic patients, Thromb Haemost 114 (2015) 289-296. 
Figure 1. Summary of results observed after DHA intake in humans and dose-related effects of DHA on human blood platelets.

For clarity, this figure only relates with low and high doses of DHA (see text for details), and shows the variations in malondialdehyde (MDA), as a global marker of oxidative stress, and vitamin E, as the main antioxidant lipid soluble vitamin.

In all DHA enrichment approaches, DHA was significantly increased in main platelet glycerophospholipids (PC and PE). This enrichment was higher after high doses compared to low doses.

\section{Highlights}

Docosahexaenoic acid exerts bimodal effects on blood platelet aggregation, oxidized-induced mononuclear cells apoptosis.

Docosahexaenoic acid at low concentrations increase vitamin $E$ whereas high concentrations tend induce oxidative stress.

Low doses of docosahexaenoic acid down regulate platelet activation and oxidative stress in diabetic and elderly subjects. 
Low dose of DHA

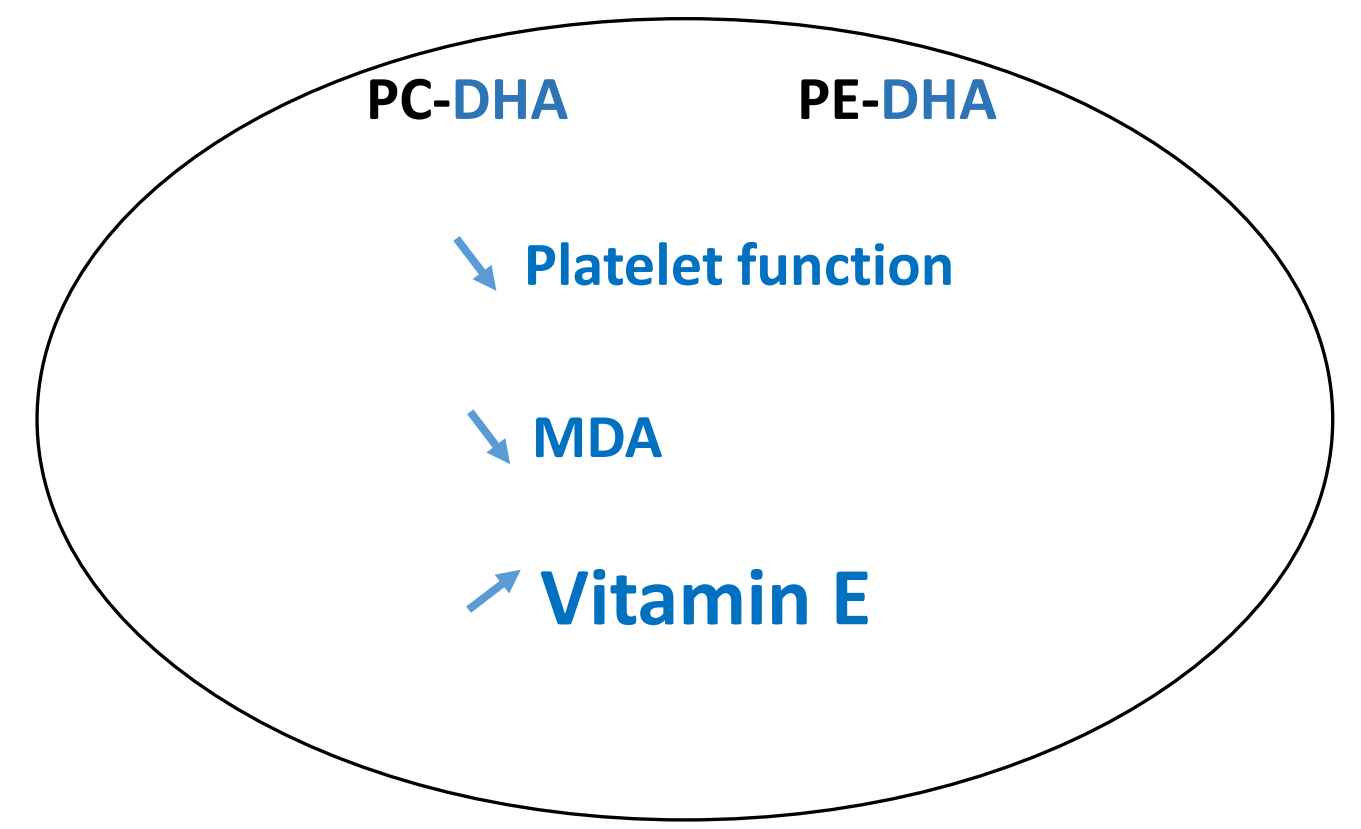

Both in vitro and ex vivo studies (elderly and healthy adults, diabetic patients)
High dose of DHA

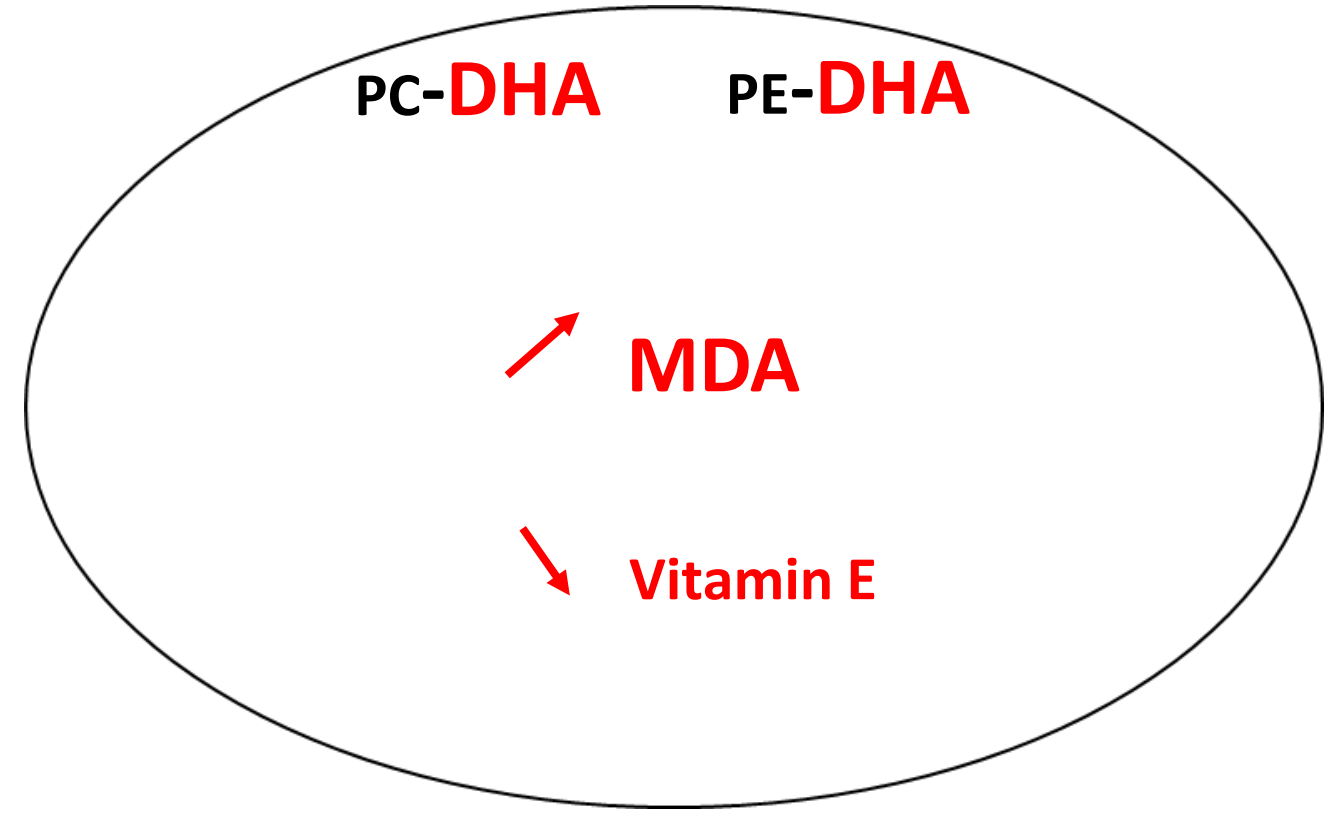

Both in vitro and ex vivo studies

(Healthy adults) 